\title{
Vaccination with B16 melanoma cells expressing a secreted form of interleukin-1 $\beta$ induces tumor growth inhibition and an enhanced immunity against the wild-type B16 tumor
}

\author{
Olle Björkdahl, ${ }^{1}$ Mikael Dohlsten, ${ }^{1,2}$ and Hans-Olov Sjögren ${ }^{1}$ \\ ${ }^{1}$ Department of Cell and Molecular Biology, Tumor Immunology Section, Biomedical Center, University of \\ Lund, Lund, Sweden; and ${ }^{2}$ AstraZeneca, R\&D Mölndal, Mölndal, Sweden.
}

We have demonstrated previously that gene transfer of the mature human interleukin-1 $\beta$ (IL-1 $\beta$ ) gene, fused to a signal sequence (ss), into mouse B16 melanoma cells results in an inhibition of their growth in vivo compared with control B16 cells. We here extend these results to show that intraperitoneal vaccinations with irradiated IL- $1 \beta$-secreting cells result in protection against subsequent subcutaneous challenge with wild-type (wt) B16 tumor cells in syngeneic C57BL/6 mice. This protection appears to be long-lasting, because rechallenge of cured mice 4 months after the first challenge also demonstrated resistance. In addition, we demonstrate that mice with established wt tumors subjected to therapeutic vaccinations with irradiated B16/ssIL-1 $\beta$ cells starting 3 days after challenge isografting have a significantly inhibited tumor growth and $25-40 \%$ survival at the challenge doses given. In vitro coculture of spleen cells from B16/ssIL-1 $\beta$ vaccinated animals and wt B16 cells induced an enhanced proliferative response, which correlated with elevated production of IL-2 and interferon- $\gamma$. A significantly enhanced cytolytic activity against B16 wt target tumor cells was observed when spleen cells from B16/ssIL-1 $\beta$ vaccinated mice were used as effector cells compared with spleen cells from control vaccinated mice. In vitro depletion experiments using anti-asialo $\mathrm{GM}_{1}$ revealed a prominent role for natural killer cells as effector cells. The data suggest that local IL-1 $\beta$ secretion during the vaccination phase can provoke or augment protective immune responses to B16 melanoma cells, which are otherwise not recorded in mice bearing B16 tumors. Cancer Gene Therapy (2000) 7, 1365-1374

Key words: Interleukin-1ß; gene therapy; signal sequence; B16; immunity.

$\mathrm{T}$ The use of recombinant cytokines and the development of gene transfer techniques have resulted in renewed enthusiasm for the concept of cancer vaccines. $^{1-6}$ The approach of cytokine gene transfer into tumor cells focuses on the therapeutic improvement of the paracrine environment of the tumor antigen (Ag) expressing cells of the tumor vaccine. Interleukin-1 (IL-1) is one of the most pleiotropic and potent cytokines with multiple antitumoral activities ${ }^{7-9}$ and has the capability to activate cells mediating both innate (macrophages, natural killer (NK) cells, and granulocytes) and adaptive ( $\mathrm{T}$ and $\mathrm{B}$ lymphocytes) immunity. ${ }^{10}$ It has important pro-inflammatory and immunostimulatory properties, activating endothelial cells, increasing costimulatory and adhesion molecules on various cell types that mediate granulocyte, monocyte, and lymphocyte recruitment, costimulating $\mathrm{T}$-cell activation, predominantly by increasing the expression of high-affinity IL-2 receptors (IL-2R) and inducing IL-2 production. ${ }^{10}$ IL-1

Received March 9, 2000; accepted July 24, 2000.

Address correspondence and reprint requests to Dr. Olle Björkdahl, Department of Cell and Molecular Biology, Tumor Immunology, BMCImmunobiology, Sölvegatan 19, S-223 62 Lund, Sweden. E-mail address: olle.bjorkdahl@wblab.lu.se is expressed and produced by a number of cells but is mainly produced by activated macrophages. The expression of IL- $1 \beta$ is strictly controlled by transcriptional regulation, posttranslational processing, and release of soluble neutralizing IL-1 type II decoy receptors and accumulation of intra- and extracellular IL- $1 \beta \mathrm{R}$ antagonists (IL$1 \beta \mathrm{Ra}) .{ }^{11,12}$ The protein is synthesized as a $32-\mathrm{kDa}$ inactive precursor molecule, which subsequently is processed by IL- $1 \beta$-converting enzyme (ICE) into a $17-\mathrm{kDa}$ bioactive protein. ${ }^{10}$ Moreover, IL-1 differs from most other cytokines in that it lacks a ss, which means that the protein is not actively secreted through the classical endoplasmic reticulum/Golgi pathway. The exact mechanism by which IL-1 is released has still not been determined fully, but it has been proposed that IL-1 is efficiently released only in cells undergoing apoptosis. ${ }^{13,14}$ The fact that ICE (or caspase 1) is homologous to the product of the Caenorhabditis elegans cell death gene (ced-3) and the finding that apoptosis of human peripheral monocytes is related to the activation of ICE provide support for the relation assumed between IL- $1 \beta$ release and apoptosis of the producer cell. However, it was shown very recently that a secretory route exists that uses regulated exocytosis of preterminal endocytic vesicles to transport cytosolic IL- $1 \beta$ out of the activated monocytes. ${ }^{15}$ 
In relation to tumor immunization, we have argued that to induce an optimal early inflammation and recruitment of immune cells to the immunization/tumor site, IL- $1 \beta$ should be released at an early stage. For that purpose, we have developed a biological model in which IL-1 $\beta$ expression can be targeted extracellularly without affecting the viability of the producer cell. This was done by ligating a ss, derived from the structurally related mouse IL-1Ra, to the mature human form of IL- $1 \beta$ (ssIL-1 $\beta$ ). Transfection of this construct to tumor cell lines resulted in the release of large amounts of IL- $1 \beta$, whereas the mature form of IL- $1 \beta$ without a ss accumulated intracellularly. ${ }^{16}$ Furthermore, we have shown previously that subcutaneous (s.c.) inoculations of live ssIL$1 \beta$-transduced B16F10 mouse melanoma cells results in reduced tumor growth and in prolonged survival compared with tumor cells transfected with IL- $1 \beta$ without the ss or mock-transfected cells. This growth inhibition was correlated with infiltration of macrophages, $\mathrm{CD} 4^{+} \mathrm{T}$ cells, and dendritic cells into the tumor area. ${ }^{7}$

In the present study, we have extended the analysis in the B16 model by evaluating the potential of IL- $1 \beta$ secretion during the vaccination phase to generate immunity against the wild-type (wt) B16 tumor. We present data showing that in the B16 melanoma model, in which nontransduced irradiated cells possess little or no ability to stimulate systemic antitumoral immunity, vaccination with irradiated tumor cells engineered to actively secrete IL-1 $\beta$ stimulates a long lasting antitumoral immunity against the wt B16F10. Characterization of the immune response induced by IL- $1 \beta$-secreting B16 cells suggested that the antitumoral immune response was T cell-dependent and skewed toward a T helper 1 (Th1) profile. In addition, an enhanced lytic activity was recorded that was mediated at least in part by NK cells.

\section{MATERIALS AND METHODS}

\section{Tumor cell line and culture condition}

B16F10 is a spontaneously derived malignant melanoma of C57BL/6 origin. ${ }^{17}$ The parental B16 cell line and the B16 transfectants were cultured in complete medium (RPMI 1640) supplemented with $2 \mathrm{mM}$ glutamine and $10 \%$ fetal calf serum (FCS) (R10). The transfectants were selected in $0.5 \mathrm{mg} / \mathrm{mL}$ G418 (Life Technologies, Gaithersburg, Md) and checked for stability of IL- $1 \beta$ expression. The YAC-1 mouse cell line was cultured in complete medium (RPMI 1640) supplemented with $2 \mathrm{mM}$ glutamine and 5\% FCS (R5). The mixed lymphocyte tumor cell cultures (MLTCs) were grown in R10 containing 50 $\mu \mathrm{M}$ 2-mercaptoethanol.

\section{Retroviral vector design and transduction of tumor cells}

The construction of the IL- $1 \beta$ expression vectors used and the generation of IL- $1 \beta$-producing cell lines have been described in detail previously. ${ }^{16}$ Briefly, the GP + E-86 packaging cell lines ${ }^{18}$ producing the different viruses were generated using Transfectam (Promega, Madison, Wis) in accordance with the manufacturer's instructions. The B16F10 mouse melanoma cell line, stably transduced with the mature form of human IL-1 $\beta$ fused with a ss derived from the structurally related
IL-1Ra, was generated by retroviral infection as described previously. ${ }^{18}$ Briefly, $1 \times 10^{5}$ B16F10 cells were seeded in $25-\mathrm{cm}^{2}$ flasks in complete medium (RPMI 1640; Life Technologies, Paisley, UK) supplemented with $2 \mathrm{mM}$ glutamine and $10 \%$ FCS and allowed to adhere overnight. A total of $1 \mathrm{~mL}$ of filter sterilized viral supernatant from the GP + E/pLXSN or $\mathrm{GP}+\mathrm{E} / \mathrm{ss} I \mathrm{~L}-1 \beta$ transfectants was added to the B16 cells together with polybrene (Sigma, St. Louis, Mo) in a final concentration of $4 \mu \mathrm{g} / \mathrm{mL}$. After incubation for 2 hours at $37^{\circ} \mathrm{C}, 4 \mathrm{~mL}$ of complete medium was added; after 48 hours, the transduced cells were selected in medium containing 0.5 $\mathrm{mg} / \mathrm{mL}$ Geneticin (G418) (Life Technologies AB, Täby, Sweden). Confluent cells were harvested and seeded at 0.5 cells/ well in 96-well plates to obtain clones. After 3-4 weeks, when clones were established, supernatants were analyzed for IL- $1 \beta$ content by enzyme-linked immunosorbent assay (ELISA). ${ }^{19}$ The clones expressing the highest levels of IL- $1 \beta$ were chosen for further studies. The clones were regularly analyzed by ELISA for IL- $1 \beta$ production.

\section{ELISA for cytokines}

IL-1 $\beta$ content in supernatants from B16 transfectants was assessed by ELISA as described previously. ${ }^{7,19}$ Supernatants from the MLTC were collected from day 1 to day 6 and were analyzed for cytokine content. The optimized ELISA immune assay (OptEIA) sets (PharMingen, San Diego, Calif) were used for detection of IL-2, IL-4, IL-10, tumor necrosis factor- $\alpha$ (TNF- $\alpha$ ), and interferon- $\gamma(\mathrm{IFN}-\gamma)$ and were performed according to the manufacturer's instructions.

\section{In vivo tumor vaccination and challenge studies}

Female C57BL/6 mice and $n u / n u$ mice were obtained from Bomholtgaard (Ry, Denmark). Mice were kept under standardized conditions and were used after they reached the age of 8-12 weeks. Tumor growth was analyzed by s.c. inoculations of different doses of viable B16F10 cells (wt) in the right flanks of the mice. When preimmunized, mice received $1 \times 10^{6}$ irradiated (80 Gy) B16/pLXSN or B16/ssIL-1 $\beta$ transfectants intraperitoneally (i.p.) at days -20 and -7 and were subsequently challenged with parental B16F10 cells on day 0 . For therapeutic vaccinations (i.e., after challenge of parental B16F10 cells), the irradiated B16 transfectants were inoculated on days 3 and 10 after B16 inoculation. The cells were suspended to the appropriate concentration and injected in 0.2 $\mathrm{mL}$ of phosphate-buffered saline (PBS) containing 1\% syngeneic mouse sera. Tumor development was analyzed by palpation of the mice two to three times a week. Mice that did not develop tumors within 100-120 days after the tumor challenge were rechallenged s.c. with $3 \times 10^{4}$ or $1 \times 10^{5} \mathrm{~B} 16(\mathrm{wt})$ cells. As controls, naive $\mathrm{C} 57 \mathrm{BL} / 6$ mice were challenged with the same tumor doses.

\section{Collection of peritoneal cells and spleen cells}

Mice that survived the first tumor challenge for $>100$ days were reimmunized i.p. with $1 \times 10^{6}$ irradiated parental B16 cells. Spleen cells and peritoneal cells were collected after 3 days. The latter were obtained by inoculation of $4 \mathrm{~mL}$ of PBS into the peritoneal cavity, gentle massaging of the abdomen, and reintroduction of the needle and aspiration of the peritoneal fluid. The cells were counted and washed further in PBS $/ 0.5 \%$ bovine sera albumin (BSA) before being used for fluorescence-activated cell sorter (FACS) analysis. A singlecell suspension of spleen cells was obtained by mechanical dissociation. Red blood cells were lysed, and cell debris was 
removed. Cells were further washed in PBS/0.5\% BSA before being used for FACS analysis.

\section{FACS analysis}

Cells were suspended in PBS/0.5\% BSA. Nonspecific binding was always blocked by pretreatment of the cells with the monoclonal antibody (mAb) 2.4G2 directed against the Fc $\gamma$ III/II (CD16/CD32) (5 $\mu \mathrm{g} / \mathrm{mL})$. Cells were incubated with $0.5-2 \mu \mathrm{g} / \mathrm{mL}$ of the relevant $\mathrm{mAb}$ for 30 minutes at $4^{\circ} \mathrm{C}$ and washed twice. The following fluorescein isothiocyanate- or phycoerythrin-conjugated mAbs were used: Rat anti-mouse CD4 (clone GK-1.5), rat anti-mouse CD8 (clone 53-6.7), rat anti-mouse Ly-6G (Gr-1) (clone RB6-8C5), rat anti-mouse CD25 (clone PC61), anti-mouse NK-1.1 (clone PK136) (all purchased from PharMingen), and rat anti-mouse F4/80 (clone MCA 497) (purchased from Serotec, Oxford, UK). Flow cytometric analysis was performed using standard settings on a FACScan flow cytometer (BD BioSciences, Stockholm, Sweden).

\section{Proliferation and cytotoxicity assays}

Spleens from nonimmunized mice or mice immunized twice i.p. (days -20 and -7 ) with B16/pLXSN or B16/ssIL-1 $\beta$ were removed from $\mathrm{C} 57 \mathrm{BL} / 6$ mice (day 0); single-cell suspensions were created by mechanical dissociation and removal of cell debris. Red cells were lysed and cells were washed and counted. For determination of proliferation, the spleen cells were cultured together with irradiated B16 (wt) cells in 96-well plates at a 40:1 ratio (responder to stimulator). The plates were incubated for $1-6$ days at $37^{\circ} \mathrm{C}$. A total of $0.5 \mu \mathrm{Ci}\left[{ }^{3} \mathrm{H}\right]$ thymidine was added to each well during the last 5 hours of incubation. The plates were harvested and analyzed for thymidine incorporation into DNA. Radioactivity was measured in a $\beta$-counter. In addition, supernatants from the MLTCs were collected from day 1 to day 6 and were analyzed for cytokine content (see above). For cytotoxicity analysis, the spleen cells were restimulated with irradiated B16 (wt) cells (20:1 ratio) in $80-\mathrm{cm}^{2}$ culture flasks for 5 days. The cells were washed, and serial dilutions of the effector cells were cocultured with $5 \times 10^{3}{ }^{51} \mathrm{Cr}$-labeled target cells in 200- $\mu \mathrm{L}$ flat-bottom 96-well plates. After 4 hours (YAC cells) or 12 hours (B16 cells) of incubation in $37^{\circ} \mathrm{C}, 25 \mu \mathrm{L}$ of supernatants was collected and mixed with scintillation fluid for $\gamma$ counting. The percentage of specific lysis was calculated using the following formula: $\left(\mathrm{cpm}_{\exp }-\right.$ $\left.\mathrm{cpm}_{\text {spontanous }}\right) /\left(\mathrm{cpm}_{\max }-\mathrm{cpm}_{\text {spontanous }}\right)$. Maximum lysis was measure as release from target cells incubated with $1 \%$ sodium dodecyl sulfate. Spontaneously released counts were always $<15 \%$ of the total counts. The data shown are the mean of triplicates, and the error bars represent SEM value.

\section{RESULTS}

\section{IL-1 $\beta$ expression of irradiated B16 transfectants}

We have previously generated B16 transfectants that efficiently release IL-1 $\beta$ extracellularly and have shown a reduced tumor growth when live B16/ssIL-1 $\beta$ transfectants were inoculated s.c. into syngeneic C57BL/6 mice, compared with mock-transduced B16 cells. ${ }^{7}$ In the present study, we wanted to examine whether vaccination with irradiated B16/ssIL-1 $\beta$ transfectants is capable of inducing systemic antitumoral immunity against the parental B16 tumor.

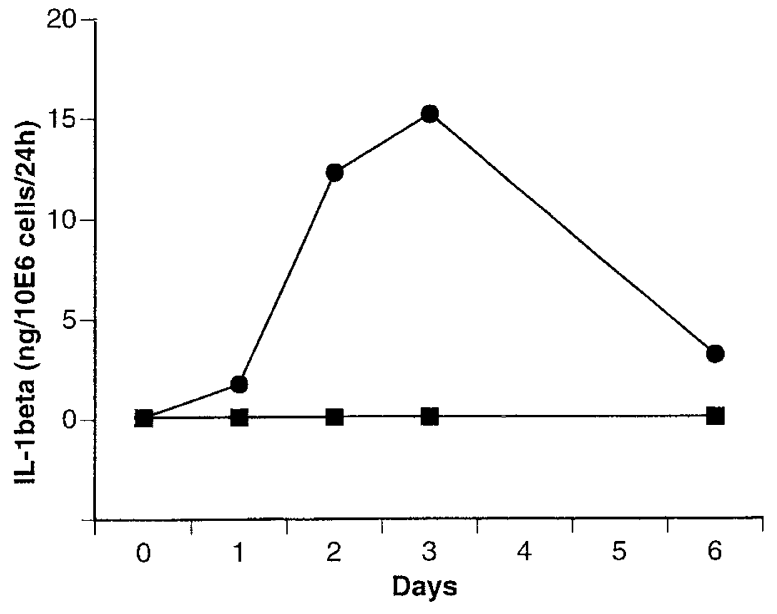

Figure 1. IL-1 $\beta$ secretion from irradiated B16 transfectants. B16/ pLXSN $(\square)$ and B16/ssIL-1 $\beta(0)$ were irradiated (80 Gy), and $1 \times 10^{6}$ cells were plated and cultured in vitro for 6 days. Supernatants were harvested and analyzed for IL- $1 \beta$ content by ELISA. Supernatants were collected at $1,2,3$, and 6 days postirradiation. Supernatants were harvested 24 hours before each timepoint to be tested, and fresh medium was added. Results are presented from one representative experiment of two performed.

Analysis of supernatants of cultured irradiated (80 Gy) B16/ssIL-1 $\beta$ transfectants for IL- $1 \beta$ content by ELISA showed that the irradiation per se did not abrogate the cytokine release. Significant amounts of released IL- $1 \beta$ were detected in supernatants during the 6-day period that was studied, and peak levels of IL- $1 \beta$ were seen on day 3 . In contrast, no IL- $1 \beta$ was detected in supernatants from the mock-transduced B16 cells (Fig 1). During the first 24 hours, the levels of IL- $1 \beta$ produced by the irradiated B16 transfectants were similar to the levels produced by nonirradiated B16 transfectants $\left(1.8\right.$ vs. $2.5 \mathrm{ng} / 1 \times 10^{6}$ cells $/ 24$ hours). During later timepoints (days 2, 3, and 6), unirradiated transfectants produced much higher levels of IL- $1 \beta$ as a result of the increased cell number (data not shown).

Vaccination with B16/ss/L-1 $\beta$ cells protects against challenge with parental B16 cells

For systemic vaccination studies, animals received $1 \times$ $10^{6}$ irradiated cells i.p. on days -21 and -7 and were subsequently challenged s.c. in the right flank with indicated doses of live nontransduced B16 cells on day 0 . Vaccination with irradiated B16/ssIL- $1 \beta$ resulted in potent antitumoral immunity against a subsequent challenge with B16 (wt) cells. All of the animals receiving the lower challenge dose $\left(3 \times 10^{4}\right.$ cells $)$ and most of the animals $(78 \%)$ receiving the higher dose $\left(1 \times 10^{5}\right.$ cells $)$ remained tumor free after 100 days (Fig 2A and Table $1)$. These doses are $\sim 30$ - and 100 -fold greater than the minimum dose that forms tumors in nonvaccinated C57BL/6 mice. Interestingly, this systemic immunity seemed to be long-lasting. Mice that had been tumor free for $>100$ days were completely protected against a 
A
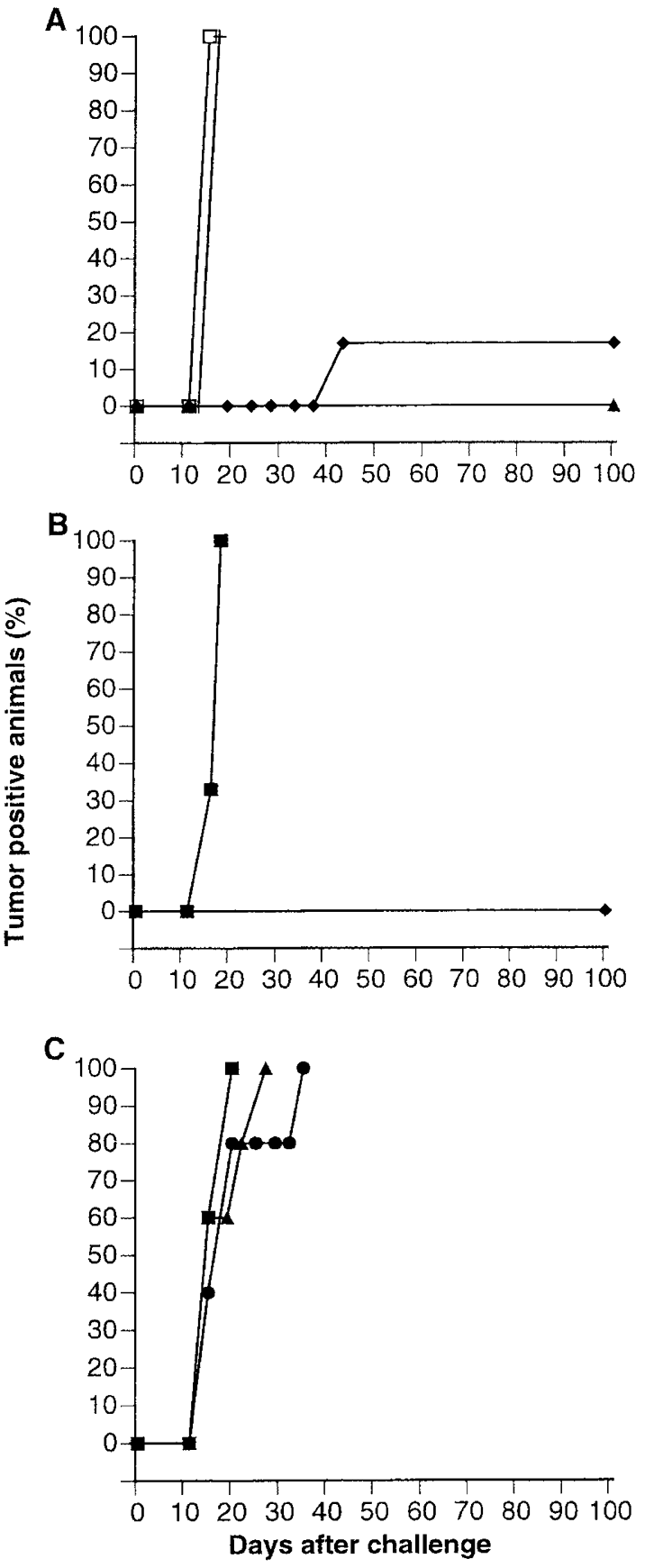

Figure 2. Prevaccination with irradiated $\mathrm{B} 16 / \mathrm{ssIL}-1 \beta$ cells protects against a subsequent challenge with B16 (wt) cells. A: Syngeneic mice were vaccinated i.p. on days -20 and -7 with $1 \times 10^{6}$ B16/pLXSN and B16/ssIL- $1 \beta$ cells, respectively, and were subsequently challenged with $3 \times 10^{4}$ (or $1 \times 10^{5}$ ) B16 (wt) cells s.c. in the right flank (six mice per group). Mice were examined for tumor growth by palpation two to three times per week. $\square$, Untreated; + , B16/pLXSN; $\boldsymbol{\Delta}$, $\mathrm{B} 16 / \mathrm{sslL}-1 \beta$; $\bullet$ B16/sslL-1 $\beta$ (challenge dose $1 \times 10^{5}$ ). B: Mice that rejected a subsequent challenge with $3 \times 10^{4}$ (wt) B16 cells after i.p. immunization with B16/ssIL-1 $\beta$ were rechallenged with $1 \times 10^{5} \mathrm{~B} 16$ cells $(\downarrow) 120$ days after the first challenge (five mice per group). As a control, naive C57BL/6 mice were challenged with the same dose ( $\square$ ). C: Nude mice were vaccinated as in (A) and were subsequently challenged with $3 \times 10^{4} \mathrm{~B} 16$ (wt) cells s.c. in the right flank (five mice

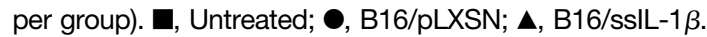

s.c. rechallenge with B16 (wt) cells, in contrast to control naive mice, in which the B16 cells grew progressively (Fig 2B). To investigate whether the presence of T cells was of importance for the prevention of tumor growth, $n u / n u$ mice were prevaccinated with irradiated B16/ ssIL-1 $\beta$ cells and subsequently challenged with $3 \times 10^{4}$ or $3 \times 10^{3}$ nontransduced B16 cells. In contrast to vaccination of $\mathrm{C} 57 \mathrm{BL} / 6$ mice, the vaccination of nude mice with B16/ssIL-1 $\beta$ failed to induce significant tumor retardation, and no difference in the frequency of tumorpositive mice were recorded between B16/ssIL- $1 \beta$-immunized mice and control-immunized mice (Fig $2 \mathrm{C}$ and Table 1). This implicates a T-cell-dependent effector mechanism. Furthermore, therapeutic vaccinations of mice with pre-existing B16 (wt) tumors resulted in significantly retarded tumor growth (data not shown) and in permanent survival of $25-40 \%$ of the mice challenged with $1 \times 10^{4}$ and $3 \times 10^{4}$ cells (Fig 3 and Table 1).

Characterization of the immune response stimulated by IL-1 $\beta$-secreting $B 16$ cells

Examination of the vaccination site by peritoneal wash 5 days after the second i.p. immunization showed that vaccination with irradiated B16/ssIL- $1 \beta$ cells resulted in an extensive infiltration of monocytes and neutrophils and in a moderate infiltration of $\mathrm{CD}^{+}$ and $\mathrm{CD} 8^{+} \mathrm{T}$ lymphocytes into the peritoneal cavity. In contrast, only a mild infiltration consisting predominantly of monocytes was seen in animals vaccinated with B16/pLXSN compared with nonimmunized mice (data not shown). The total number of cells obtained from the peritoneal wash after the B16/ssIL- $1 \beta$ immunizations increased 4- to 5-fold compared with B16/ pLXSN vaccinated or untreated mice (data not shown). Moreover, mice that had been tumor free for 120 days after challenge with tumor cells subsequent to preimmunization with $\mathrm{B} 16 / \mathrm{ss} I \mathrm{~L}-1 \beta$ were again immunized once with $1 \times 10^{6}$ irradiated parental B16 cells. Spleen T cells were analyzed 3 days after the immunization by FACS analysis for CD25 expression. Because mice were protected against challenge with B16 (wt) tumor at this timepoint, and because B16/ ssIL-1 $\beta$ immunizations of nude mice did not protect against a parental tumor challenge, we expected an increased number of $\mathrm{T}$ cells with activated phenotype. Indeed, analysis of a limited number of mice (four mice) consistently showed a significantly increased proportion of $\mathrm{CD} 25^{+} \mathrm{CD} 4^{+}$spleen cells in previously cured mice compared with naive mice immunized with wt tumor (Fig 4, A and B). Similar results were obtained when analyzing i.p. $\mathrm{CD}^{+} \mathrm{T}$ cells (data not shown). The level of $\mathrm{CD} 4{ }^{+} \mathrm{CD} 25^{+}$cells after immunization of naive mice with $\mathrm{B} 16 \mathrm{wt}$ cells did not differ from the level observed for untreated mice (data not shown). In contrast to these findings with $\mathrm{CD}^{+}{ }^{+} \mathrm{T}$ cells, very few $\mathrm{CD}^{+} \mathrm{T}$ cells expressed CD25 (Fig 4, C and D). 
Table 1. Vaccination with IL-1 $\beta$-Secreting B16 Cells Enhances the Survival After Challenge with B16 Wt Cells

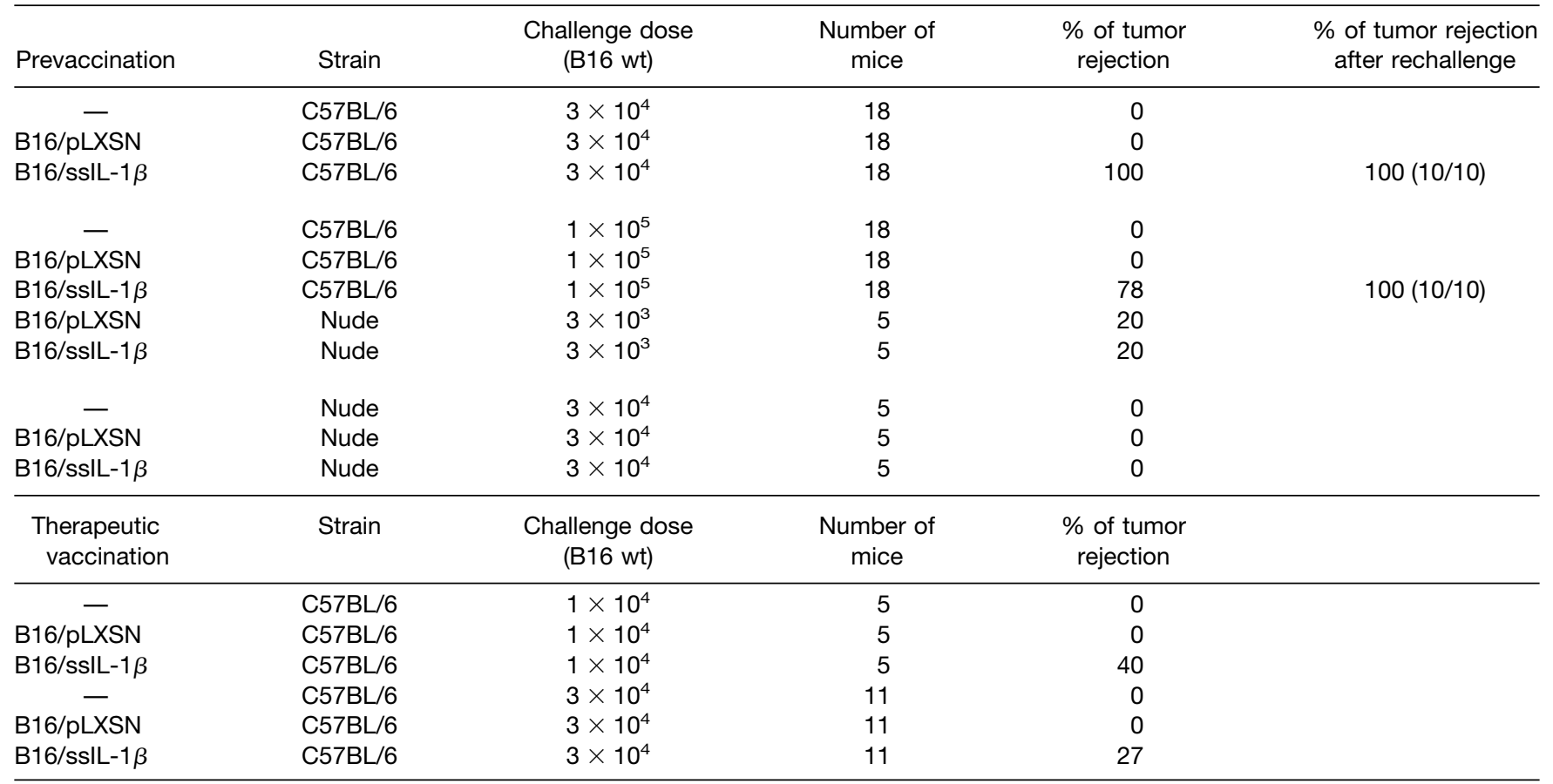

Spleen cells derived from mice immunized with irradiated B16/sslL-1 $\beta$ cells showed an enhanced in vitro proliferative antitumoral response, release of $I L-2$ and IFN- $\gamma$, and cytolytic activity

We subsequently tested whether spleen cells from animals immunized i.p. were able to generate a proliferative response when restimulated in vitro with B16 parental cells. Compared with controls, spleen cells obtained

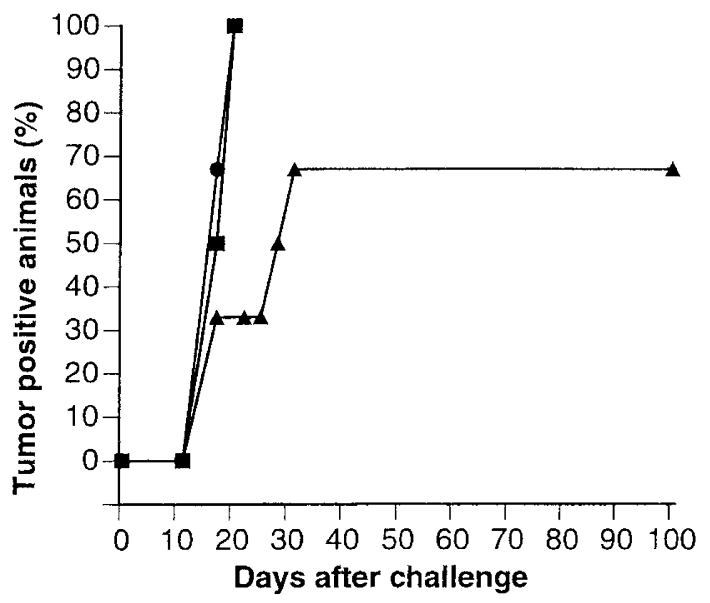

Figure 3. Reduced tumor growth rate and increased survival of mice therapeutically vaccinated with $\mathrm{B} 16 / \mathrm{ss} \mathrm{L}-1 \beta$. Mice were vaccinated i.p. with $1 \times 10^{6}$ irradiated B16/pLXSN $(\bullet)$ or B16/ssIL-1 $\beta(\mathbf{\Delta})$ cells 3 and 10 days after s.c. challenge with $3 \times 10^{4} \mathrm{~B} 16$ wt cells (five to six mice per group). Unimmunized mice served as controls ( $\square$ ). Mice were examined for tumor development by palpation two to three times per week. Results are presented from one representative experiment of two performed. from mice 7-10 days after immunization with irradiated IL- $1 \beta$-secreting B16 cells displayed a significantly higher B16-specific proliferative response, peaking on day $4-5$
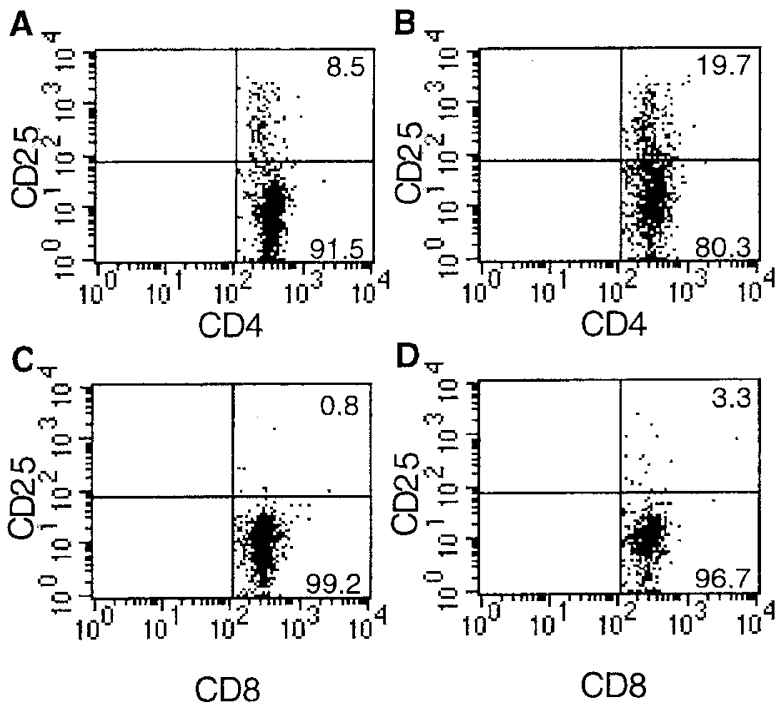

Figure 4. Previously cured mice up-regulate CD25 on splenic CD4 ${ }^{+}$ T cells after immunization with B16 (wt) cells. Mice that had been tumor free for 120 days after having been immunized with irradiated B16/sslL-1 $\beta$ cells and having rejected a subsequent challenge of B16 $(\mathrm{wt})$ cells were again immunized with $1 \times 10^{6}$ irradiated parental B16 cells. Splenic T cells were subjected to FACS analysis 3 days later to determine level of CD25 up-regulation. (A) and (B) show the CD25 expression on $\mathrm{CD}^{+}{ }^{+} \mathrm{T}$ cells from naive and primed mice, respectively. (C) and (D) show the CD25 expression on $\mathrm{CD}^{+} \mathrm{T}$ cells from naive and primed mice, respectively. Results are presented from one representative experiment of four performed. 


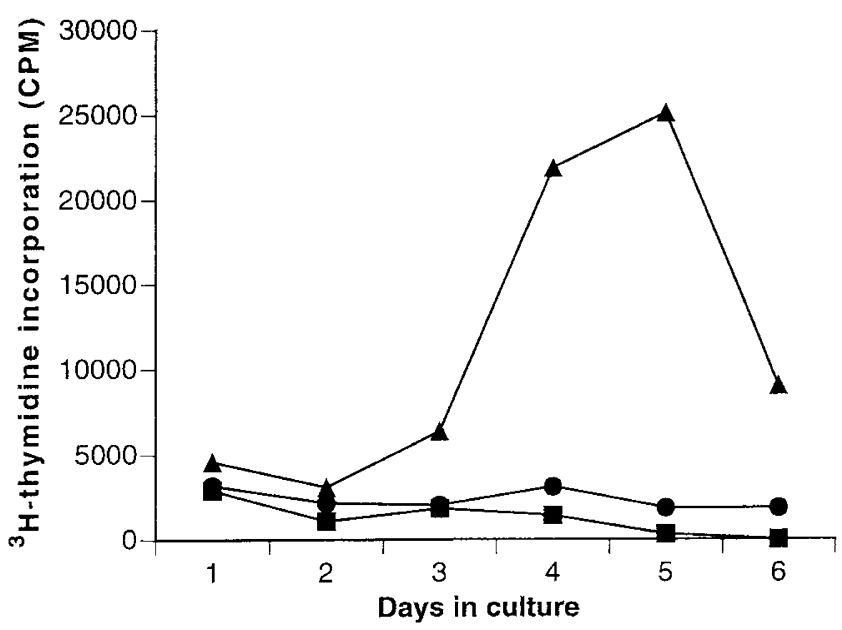

Figure 5. Enhanced in vitro proliferative response of spleen cells after in vivo immunization with B16/ssIL-1 $\beta$. Spleen cells from unimmunized mice $(\square)$ or mice immunized with B16/pLXSN (circf]) or B16/ssIL-1 $\beta(\mathbf{A})$ cells $\left(2 \times 10^{5}\right.$ cells/well) were cocultured for $1-6$ days with irradiated $(80 \mathrm{~Gy}) \mathrm{B} 16(\mathrm{wt})$ cells $\left(5 \times 10^{3}\right.$ cells/well) in 96-well plates. To determine the proliferative response, $0.5 \mu \mathrm{Ci}$ $\left[{ }^{3} \mathrm{H}\right]$ thymidine was added to each well during the last 5 hours of incubation. The plates were harvested and analyzed for thymidine incorporation. Radioactivity was measured in a $\beta$-counter. Results are presented from one representative experiment of three performed.

(Fig 5). Moreover, splenocytes derived from the various groups did not proliferate in the absence of stimulator cells (data not shown). Similarly, stimulator cells did not proliferate after they had been irradiated previously with 80 Gy (data not shown). The enhanced proliferative response of spleen cells derived from the B16/ssIL-1 $\beta$ immunized mice correlated with an enhanced cytokine secretion. Restimulated cells derived from animals previously immunized with IL- $1 \beta$-secreting B16 cells produced high levels of IFN- $\gamma$ (Fig 6A) and moderate levels of IL-2 (Fig 6B) compared with controls. In contrast, low or undetectable levels of IL-4, IL-10, and TNF- $\alpha$ were recorded, with no differences between the groups. Thus, it seems that the activated B16-specific $\mathrm{T}$ cells are primarily of Th1 type. The lytic activity (12-hour ${ }^{51} \mathrm{Cr}$ release assay) of spleen effector cells after in vivo immunization with irradiated B16/pLXSN or B16/ ssIL-1 $\beta$ was assessed after a 5-day restimulation with irradiated B16 (wt) cells. Vaccination with B16/ssIL-1 $\beta$ cells resulted in a significantly enhanced lytic activity against B16 (wt) target cells (Fig 7A). An $\sim 2.5$-fold $(26.8 \%$ vs. $10.6 \%)$ increase in target cell lysis was recorded compared with spleen cells derived from B16/ pLXSN-vaccinated animals. As could be anticipated in view of the elevated levels of the NK-activating cytokines IFN- $\gamma$ and IL- 2 produced by spleen cells of B16/ssIL$1 \beta$-immunized donors, these cells have an enhanced lytic activity against the NK-sensitive YAC target cells (data not shown). Because B16 tumor cells are known to be sensitive to the effect of NK cells, we investigated the role of NK cells as effector cells by depleting them after
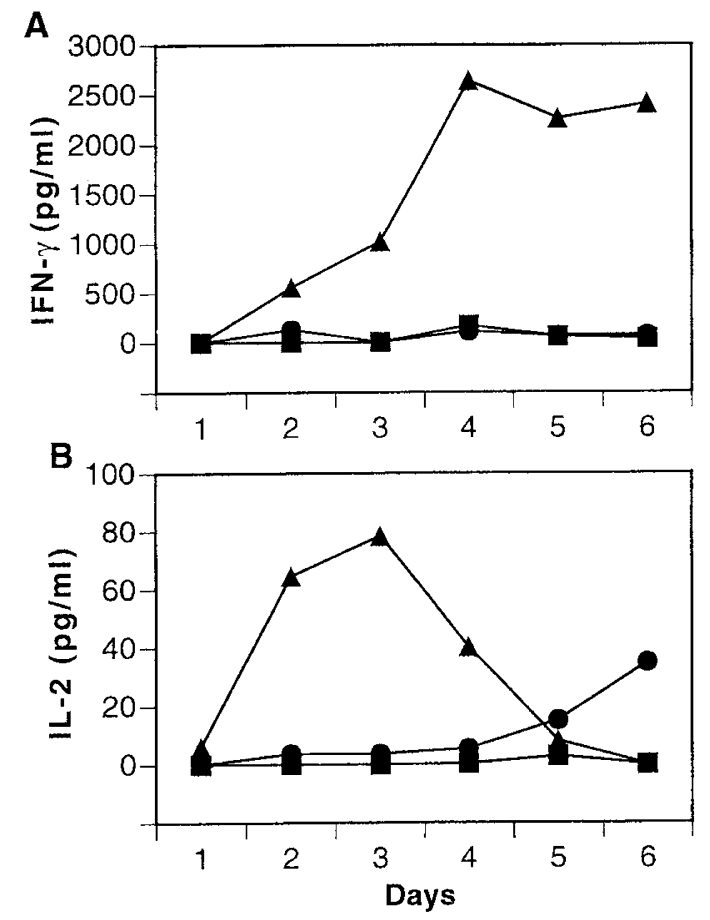

Figure 6. Production of IL-2 and IFN- $\gamma$ release after restimulation of spleen cells from B16/sslL-1 $\beta$ immunized mice. Spleen cells $(2 \times$ $10^{5}$ cells/well) from unimmunized mice $(\square)$ or mice immunized with B16/pLXSN (O) or B16/ssIL-1 $\beta(\mathbf{\Delta})$ cells were cocultured for 1-6 days with irradiated (80 Gy) B16 (wt) cells $\left(5 \times 10^{3}\right.$ cells/well) in 96-well plates. Supernatants were collected each day and were

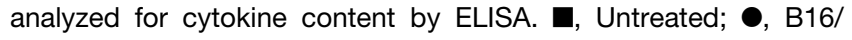
pLXSN; $\mathbf{\Delta}, \mathrm{B} 16 / \mathrm{ss} \mid \mathrm{L}-1 \beta$. Results are presented from one representative experiment of two performed.

restimulation and before cytotoxicity assay. NK cell depletion resulted in a considerable reduction in lytic activity compared with nondepleted effector cells, but a significant part of the cytotoxicity remained (Fig 7B). In contrast, the lytic activity mediated by spleen effector cells derived from B16/pLXSN-immunized mice was completely eliminated by NK cell depletion, indicating that the lytic activity recorded after B16/pLXSN immunization was dominantly mediated by NK effector cells. However, as judged by FACS analysis of the depleted spleen cells, using an activated lymphocyte gate, removal of NK cells from the effector spleen cells was not entirely complete, neither with cells of immunized nor nonimmunized donors.

\section{DISCUSSION}

Immune responses can indeed be generated against most tumors, including those that have previously been regarded as "nonimmunogenic." It is now well known that several, and perhaps all, spontaneous tumors do express tumor Ags. A number of tumor Ags have been identified, and new Ags are continuously being isolated. ${ }^{5,20}$ Nonetheless, the immune system normally fails to 
A

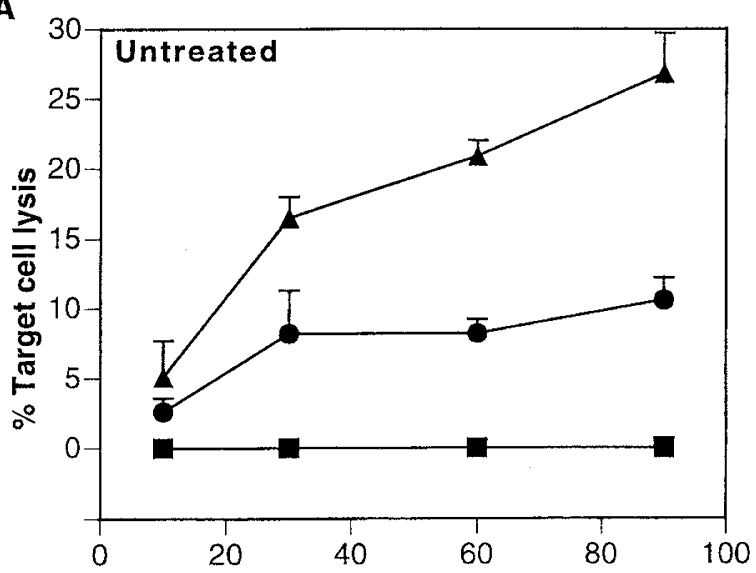

B

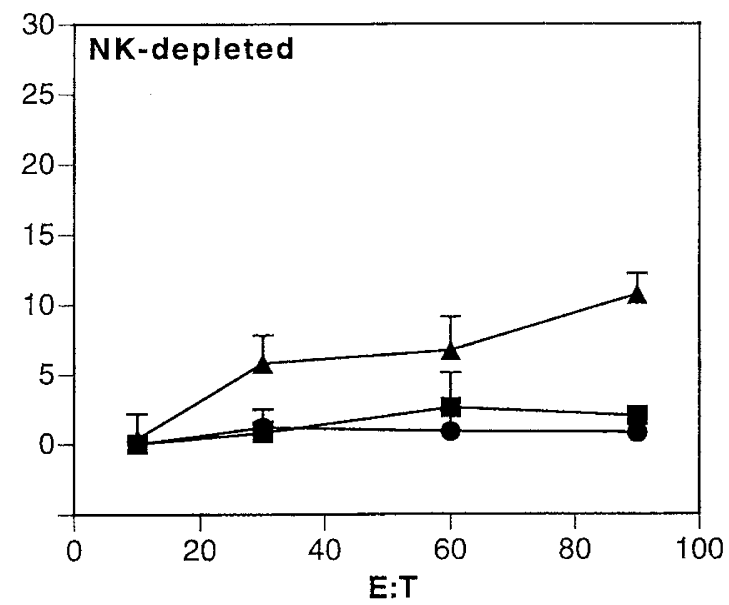

Figure 7. Immunization with $\mathrm{B} 16 / \mathrm{ss} \mathrm{L}-1 \beta$ induces an enhanced cytolytic activity of spleen cells in vitro against B16 (wt) target cells. A: Spleen cells from unimmunized mice $(\square)$ or mice immunized with $\mathrm{B} 16 / \mathrm{pLXSN}(\mathbf{0})$ or B16/ssIL-1 $\beta(\mathbf{\Delta})$ cells were restimulated for 5 days with irradiated B16 (wt) cells (20:1 ratio) in $80-\mathrm{cm}^{2}$ culture flasks. The cells were washed and cocultured at various ratios with ${ }^{51} \mathrm{Cr}$-labeled B16 target cells $\left(5 \times 10^{3}\right.$ cells/well $)$ in $200-\mu \mathrm{L}$ flat-bottom wells. After 12 hours of incubation at $37^{\circ} \mathrm{C}, 25 \mu \mathrm{L}$ of supernatant was collected for $\gamma$ counting. B: The effector cells were depleted of NK cells after the restimulation, before the 12 -hour ${ }^{51} \mathrm{Cr}$ release assay was performed. Results are presented from one representative experiment of two performed. Error bars represent SEM of triplicates.

mount a protective immune response against such tumors, which appears to be due to activation of various immunosuppressive mechanisms by the tumor growth, inhibiting an efficient immune response toward the Ags expressed. One approach to augment the immune responses against tumors has been to genetically modify tumor cells by gene transfer to express immunostimulatory molecules such as membrane-bound costimulatory molecules or cytokines. ${ }^{3,21}$ Transfer of cytokine genes into tumor cells more closely reflects the physiological mode of action of cytokine secretion during an immune response compared with systemic cytokine administration. In addition, cytokines delivered systemically often result in unwanted side effects, at least at the doses needed to obtain appropriate concentrations at the vaccination/tumor site.

In this study, we have evaluated the biological effects of human IL- $1 \beta$ to increase an antitumoral immune response against the mouse melanoma B16 tumor. The rationale for using human IL- $1 \beta$ was to make it possible to distinguish the introduced gene product from endogenous murine IL- $1 \beta$. There is an extensive sequence homology between the mouse and human IL- $1 \beta$ gene products $(\sim 85 \%)$, and human IL- $1 \beta$ shows strong bioactivity against both mouse and human T cells. Although we cannot rule out the possibility that an immune response may be induced against the human IL- $1 \beta$, such a response would not affect the wt target tumor cells used to evaluate the antitumoral response. A number of biological properties of IL-1 make it tempting to speculate that this molecule may be a potent stimulator of a weak antitumoral immune response. It has been suggested that proinflammatory cytokines, such as IL-1 and TNF- $\alpha$, may play a crucial role in generating productive Th cells and a sustained immune response, in contrast to transient T-cell activation alone in the absence of such cytokines. ${ }^{22}$ Furthermore, IL-1 is known to be capable of activating a number of antitumoral mechanisms, such as the enhancement of cytolytic activity of T lymphocytes, monocytes, and NK cells. ${ }^{23-25}$ IL-1 is able to enhance the expression of other cytokine genes, such as IL-2, granulocyte-macrophage colony-stimulating factor, and IFN- $\gamma$, which all have been shown to inhibit tumor growth in various tumor models. ${ }^{26-28}$ IL- 1 and IFN- $\gamma$ also act synergistically to increase the tumoricidal activities of macrophages. ${ }^{29}$ Finally, the immunogenicity of transformed murine fibroblasts or T-lymphoma cells has been shown to be enhanced by induction of constitutive or short-term IL- $1 \alpha$ production in the cells, either by transfection or by immune activation. Regression of the IL- $1 \alpha$-producing cells resulted in specific antitumoral immune responses and in inhibited growth of a subsequent parental tumor challenge. Moreover, therapeutic vaccinations of mice with established parental tumors significantly enhanced the survival. ${ }^{9,30}$ This is of relevance, because IL- $1 \alpha$ and IL- $1 \beta$ share a number of biological properties and bind to the same IL-1R. ${ }^{8,31} \mathrm{We}$ show that local IL- $1 \beta$ secretion from genetically modified B16 cells recruits and increases the activation of immunocompetent cells during the vaccination phase, leading to antitumoral immunity against the poorly immunogenic parental tumor. I.p. immunizations with irradiated B16 cells, genetically modified to secrete the mature bioactive form of IL-1 $\beta$, resulted in protection against a subsequent challenge of the parental B16 melanoma. Interestingly, when such protected mice were rechallenged with parental B16 tumor cells $>100$ days later, they rejected the challenge tumor, indicating that the immunization had induced a specific longlasting tumor immunity rather than merely a nonspecific inflammatory reaction. Moreover, therapeutic vaccinations initiated 3 days after challenge with wt tumor resulted in significant tumor growth inhibition and cure 
in $\sim 25-40 \%$ of the mice depending upon the challenge dose given. Mice left untreated or immunized with mock-transduced B16 cells all developed tumors and were sacrificed within 25-35 days. This protective effect after therapeutic vaccinations with B16/ssIL- $\beta$ was not seen in nude mice. Moreover, a significant up-regulation of the IL-2R $\alpha$-chain on $20 \%$ of splenic CD4 ${ }^{+} \mathrm{T}$ cells was seen after inoculation of previously cured mice with parental B16 cells. This is to be compared with the $\sim 10 \%$ IL-2R $\alpha$-expressing cells of the splenic $\mathrm{CD} 4^{+} \mathrm{T}$ cells in untreated mice and in naive mice immunized with B16. This is also the level of CD25 expression normally observed in adult unimmunized mice. ${ }^{32} \mathrm{Al}-$ though the increase in CD25 expression was analyzed on a limited number of mice (four mice), these results, when taken together, implicate an important role for the $\mathrm{CD}^{+}{ }^{+} \mathrm{T}$ cells in mediating the tumor rejection response observed after immunization with IL- $\beta$-secreting B16 cells.

A number of recent reports have suggested that there is a correlation between the generation of a type 1 cytokine response and antitumoral activity. ${ }^{33-35}$ We found that IL- $1 \beta$ secretion during the vaccination phase skewed the tumor-specific $\mathrm{T}$ cells into a Th1 type. Significant levels of IL-2 and IFN- $\gamma$ were induced after spleen cells from B16/ssIL-1 $\beta$ immunized mice were restimulated with parental tumor cells. The in vitro cytotoxicity assay revealed a profound increase in B16 (wt) target cell lysis by spleen cells from B16/ssIL-1 $\beta$ vaccinated mice compared with controls. The fact that B16 tumor has been shown to be NK cell-sensitive and the finding that restimulated effector cells produced the potent NK activators IL- 2 and IFN- $\gamma$ made us investigate the role of NK cells as effector cells in our system. Depletion of NK cells resulted in a significant reduction in cytolytic activity, although a considerable activity was maintained. The lytic activity of spleen cells from B16/ pLXSN-immunized mice was completely removed by NK cell depletion. Because the NK cell depletion was not complete in either of the cases as judged by FACS analysis, these results cannot entirely exclude that the NK cells are the only effector cells involved in the direct tumor killing in our system. B16 cells normally express very low levels of major histocompatibility complex (MHC) class I, consistent with their NK sensitivity, ${ }^{36}$ but treatment of the B16 cells with recombinant IFN- $\gamma$ increases the expression of both MHC class I and MHC class II. It has been shown previously that IFN- $\gamma$ mediated up-regulation of MHC class I expression renders the B16 cells susceptible to specific lysis by primed cytotoxic $\mathrm{T}$ lymphocytes. ${ }^{37}$ Moreover, Levitsky et $\mathrm{al}^{38}$ have shown that immunization with granulocyte-macrophage colony-stimulating factor-transduced $\mathrm{MHC}$ class $\mathrm{I}^{-}$tumor cells resulted in rejection of $\mathrm{MHC}^{-}$ tumor challenge, and that this response was critically dependent upon $\mathrm{CD}^{+}{ }^{+} \mathrm{T}$ cells and NK cells but not on $\mathrm{CD} 8^{+} \mathrm{T}$ cells. In contrast, immunization with the MHC class $\mathrm{I}^{+}$tumor variant induced protection against a MHC class I ${ }^{+}$tumor challenge. This response required $\mathrm{CD}^{+}$and $\mathrm{CD}^{+}{ }^{+} \mathrm{T}$ cells. ${ }^{38}$ To determine whether increased expression of MHC class I and class II influenced the cytolytic activity in our model, the B16 cells were treated with recombinant murine IFN- $\gamma$ before performing the restimulation and cytotoxicity assays. The increased expression of MHC class I and class II did not significantly enhance the sensitivity to cytolytic activity in vitro compared with untreated B16 cells (data not shown). Because MHC class I expression on tumor targets has been shown to inhibit NK cell-mediated cytotoxicity ${ }^{39}$ it is tempting to speculate that both activated NK cells and $\mathrm{CD} 8^{+} \mathrm{T}$ cells play an important role as effector cells in our system, and that depending upon the level of MHC expression, which is affected by the production of IFN- $\gamma$, one or the other effector cell type may have a dominating effect.

Systemic administration of IL-1 to animals and humans has been shown to mediate antitumoral effects. However, systemic delivery has often resulted in unwanted side effects, such as fever, rigors, hypotension, headache, and fatigue. ${ }^{40-44}$ In addition, systemic administration of IL- $1 \beta$ has been reported to promote tumor metastasis in various tumor systems, which has been argued to be the result of an enhanced adhesiveness of endothelial cells and/or increased production of local growth factors. ${ }^{45-47}$

Only few studies have been published in which IL-1 $\beta$ transduced tumor cells have been evaluated for their capacity to generate antitumoral activity against parental tumors. ${ }^{48,49}$ One of the reasons for this might be that the extracellular release of IL- $1 \beta$ normally is low due to the lack of the ss, resulting in insufficient levels to generate the required early cytokine milieu for recruitment of immune cells at the vaccination site. Indeed, we found that prevaccination with B16 cells transduced with IL-1 $\beta$ without a ss did not protect against a subsequent challenge of the B16 wt tumor, although the tumor growth rate was reduced compared with control mice (data not shown). This suggests that an early IL- $1 \beta$ release is required to support the generation of an efficient antitumoral immune response. The present study shows that local active but time-limited IL- $1 \beta$ secretion during the vaccination phase can successfully enhance the immune response and mediate systemic immunity against the poorly immunogenic B16 melanoma.

\section{ACKNOWLEDGMENTS}

We thank Eva Gynnstam for her skillful technical assistance. The Swedish Cancer Society and the Swedish Medical Research council provided financial support.

\section{REFERENCES}

1. Colombo MP, Modesti A, Parmiani G, Forni G. Local cytokine availability elicits tumor rejection and systemic immunity through granulocyte-T-lymphocyte cross-talk. Cancer Res. 1992;52:4853-4857.

2. Davis BM, Koc ON, Lee K, Gerson SL. Current progress in the gene therapy of cancer. Curr Opin Oncol. 1996;8: 499-508. 
3. Dranoff G, Mulligan RC. Gene transfer as cancer therapy. Adv Immunol. 1995;58:417-454.

4. Forni G, Cavallo F, Consalvo M, et al. Molecular approaches to cancer immunotherapy. Cytokines Mol Ther. 1995;1:225-248.

5. Rosenberg SA. A new era for cancer immunotherapy based on the genes that encode cancer antigens. Immunity. 1999;10:281-287.

6. Simons JW, Mikhak B. Ex-vivo gene therapy using cytokine-transduced tumor vaccines: molecular and clinical pharmacology. Semin Oncol. 1998;25:661-676.

7. Bjorkdahl O, Gjörloff-Wingren A, Hedlund G, Ohlsson L, Dohlsten M. Gene transfer of a hybrid interleukin- $1 \beta$ gene to B16 mouse melanoma recruits leukocyte subsets and reduces tumour growth in vivo. Cancer Immunol Immunother. 1997;44:273-281.

8. Dinarello CA. Biologic basis for interleukin-1 in disease. Blood. 1996;87:2095-2147.

9. Voronov E, Weinstein Y, Benharroch D, et al. Antitumor and immunotherapeutic effects of activated invasive $\mathrm{T}$ lymphoma cells that display short-term interleukin $1 \alpha$ expression. Cancer Res. 1999;59:1029-1035.

10. Dinarello CA. Interleukin-1 and interleukin-1 antagonism. Blood. 1991;77:1627-1652.

11. Arend WP. Interleukin-1 receptor antagonist. $A d v$ Immunol. 1993;54:167-227.

12. Colotta F, Dower SK, Sims JE, Mantovani A. The type II "decoy" receptor: a novel regulatory pathway for interleukin 1. Immunol Today. 1994;15:562-566.

13. Hogquist KA, Nett MA, Unanue ER, Chaplin DD. Interleukin 1 is processed and released during apoptosis. Proc Natl Acad Sci USA. 1991;88:8485-8489.

14. Hogquist KA, Unanue ER, Chaplin DD. Release of IL-1 from mononuclear phagocytes. J Immunol. 1991;147:21812186.

15. Andrei C, Dazzi C, Lotti L, Torrisi MR, Chimini G, Rubartelli A. The secretory route of the leaderless protein interleukin $1 \beta$ involves exocytosis of endolysosome-related vesicles. Mol Biol Cell. 1999;10:1463-1475.

16. Wingren AG, Bjorkdahl O, Labuda T, et al. Fusion of a signal sequence to the interleukin- $1 \beta$ gene directs the protein from cytoplasmic accumulation to extracellular release. Cell Immunol. 1996;169:226-237.

17. Fidler IJ. Selection of successive tumour lines for metastasis. Nat New Biol. 1973;242:148-149.

18. Markowitz D, Goff S, Bank A. A safe packaging line for gene transfer: separating viral genes on two different plasmids. J Virol. 1988;62:1120-1124.

19. Kenney JS, Masada MP, Eugui EM, Delustro BM, Mulkins MA, Allison AC. Monoclonal antibodies to human recombinant interleukin-1 (IL-1) $\beta$ : quantitation of IL-1 $\beta$ and inhibition of biological activity. J Immunol. 1987; $138: 4236-4242$.

20. Boon $T$, van der Bruggen P. Human tumor antigens recognized by T lymphocytes. $J$ Exp Med. 1996;183:725729.

21. Viret C, Lindemann A. Tumor immunotherapy by vaccination with cytokine gene-transfected cells. Int Rev Immunol. 1997;14:193-212.

22. Pape KA, Jenkins MK. A role for inflammatory cytokines in the productive activation of antigen-specific $\mathrm{CD}^{+}$ T-cells. Agents Actions Suppl. 1998;49:23-31.

23. Dempsey RA, Dinarello CA, Mier JW, et al. The differential effects of human leukocyte pyrogen/lymphocyteactivating factor, $\mathrm{T}$ cell growth factor, and interferon on human natural killer activity. J Immunol. 1982;129:25042510.

24. Kiertscher SM, Mathews HL. Systemic IL-1 and adjuvant treatment of an experimental tumor: immune status during primary tumor challenge. Biotherapy. 1992;5: 259-274.

25. Onozaki K, Matsushima K, Kleinerman ES, Saito T, Oppenheim JJ. Role of interleukin 1 in promoting human monocyte-mediated tumor cytotoxicity. J Immunol. 1985; $135: 314-320$

26. Dranoff G, Jaffee E, Lazenby A, et al. Vaccination with irradiated tumor cells engineered to secrete murine granulocyte-macrophage colony-stimulating factor stimulates potent, specific, and long-lasting anti-tumor immunity. Proc Natl Acad Sci USA. 1993;90:3539-3543.

27. Gansbacher B, Bannerji R, Daniels B, Zier K, Cronin K, Gilboa E. Retroviral vector-mediated $\gamma$-interferon gene transfer into tumor cells generates potent and longlasting antitumor immunity. Cancer Res. 1990;50:78207825 .

28. Gansbacher B, Zier K, Daniels B, Cronin K, Bannerji R, Gilboa E. Interleukin 2 gene transfer into tumor cells abrogates tumorigenicity and induces protective immunity. J Exp Med. 1990;172:1217-1224.

29. Takikawa O, Oku T, Yasui H, Yoshida R. Synergism between IFN- $\gamma$ and IL- $1 \alpha / \beta$ in growth inhibition of an allografted tumor. J Immunol. 1993;151:2070-2076.

30. Apte RN, Douvdevani A, Zoller M, et al. Involvement of immune responses in the eradication of IL- $1 \alpha$ genetransduced tumour cells: mechanisms of tumour rejection and immunotherapeutical implications. Folia Biol (Praha). 1994;40:1-18.

31. Dinarello CA. The biological properties of interleukin-1. Eur Cytokine Netw. 1994;5:517-531.

32. Sakaguchi S, Sakaguchi N, Asano M, Itoh M, Toda M. Immunologic self-tolerance maintained by activated $\mathrm{T}$ cells expressing IL-2 receptor $\alpha$-chains (CD25): breakdown of a single mechanism of self-tolerance causes various autoimmune diseases. J Immunol. 1995;155:11511164.

33. Aruga A, Aruga E, Tanigawa K, Bishop DK, Sondak VK, Chang AE. Type 1 versus type 2 cytokine release by $\mathrm{V} \beta \mathrm{T}$ cell subpopulations determines in vivo antitumor reactivity: IL-10 mediates a suppressive role. J Immunol. 1997; 159:664-673.

34. Hu HM, Urba WJ, Fox BA. Gene-modified tumor vaccine with therapeutic potential shifts tumor-specific $\mathrm{T}$ cell response from a type 2 to a type 1 cytokine profile. J Immunol. 1998;161:3033-3041.

35. Zitvogel L, Mayordomo JI, Tjandrawan T, et al. Therapy of murine tumors with tumor peptide-pulsed dendritic cells: dependence on $\mathrm{T}$ cells, B7 costimulation, and $\mathrm{T}$ helper cell 1-associated cytokines. J Exp Med. 1996;183:8797.

36. Kurosawa S, Harada M, Matsuzaki G, et al. Early-appearing tumour-infiltrating natural killer cells play a crucial role in the generation of anti-tumour $\mathrm{T}$ lymphocytes. Immunology. 1995;85:338-346.

37. Bohm W, Thoma S, Leithauser F, Moller P, Schirmbeck R, Reimann J. T cell-mediated, IFN- $\gamma$-facilitated rejection of murine B16 melanomas. J Immunol. 1998;161: 897-908.

38. Levitsky HI, Lazenby A, Hayashi RJ, Pardoll DM. In vivo priming of two distinct antitumor effector populations: the role of MHC class I expression. J Exp Med. 1994;179:12151224. 
39. Kaufman DS, Schoon RA, Leibson PJ. MHC class I expression on tumor targets inhibits natural killer cellmediated cytotoxicity without interfering with target recognition. J Immunol. 1993;150:1429-1436.

40. Crown J, Jakubowski A, Kemeny N, et al. A phase I trial of recombinant human interleukin- $1 \beta$ alone and in combination with myelosuppressive doses of 5-fluorouracil in patients with gastrointestinal cancer. Blood. 1991;78:14201427.

41. Hornung RL, Kiertscher SM, Mathews HL. Systemic IL-1 and adjuvant treatment of an experimental tumor: immune status following tumor rechallenge. Biotherapy. 1992;5: 227-237.

42. Neville ME, Pezzella KM. Anti-tumour effects of interleukin $1 \beta$ : in vivo induction of immunity to B16 melanoma, a non-immunogenic tumour. Cytokine. 1994;6:310-317.

43. Smith JW, Urba WJ, Curti BD, et al. The toxic and hematologic effects of interleukin- $1 \alpha$ administered in a phase I trial to patients with advanced malignancies. J Clin Oncol. 1992;10:1141-1152.

44. Triozzi PL, Kim JA, Martin EW, Young DC, Benzies T, Villasmil PM. Phase I trial of escalating doses of interleu- kin- $1 \beta$ in combination with a fixed dose of interleukin-2. J Clin Oncol. 1995;13:482-489.

45. Garofalo A, Chirivi RG, Foglieni C, et al. Involvement of the very late antigen 4 integrin on melanoma in interleukin 1-augmented experimental metastases. Cancer Res. 1995; 55:414-419.

46. Giavazzi R, Garofalo A, Bani MR, et al. Interleukin 1-induced augmentation of experimental metastases from a human melanoma in nude mice. Cancer Res. 1990;50: 4771-4775.

47. Vidal-Vanaclocha F, Alvarez A, Asumendi A, Urcelay B, Tonino P, Dinarello CA. Interleukin 1 (IL-1)-dependent melanoma hepatic metastasis in vivo: increased endothelial adherence by IL-1-induced mannose receptors and growth factor production in vitro. J Natl Cancer Inst. 1996;88:198-205.

48. Peplinski GR, Tsung K, Meko JB, Norton JA. In vivo gene therapy of a murine pancreas tumor with recombinant vaccinia virus encoding human interleukin-1 $\beta$. Surgery. 1995;118:185-190.

49. Saito S, Bannerji R, Gansbacher B, et al. Immunotherapy of bladder cancer with cytokine gene-modified tumor vaccines. Cancer Res. 1994;54:3516-3520. 